\title{
Enhancing Cancer care of rural dwellers through telehealth and engagement (ENCORE): protocol to evaluate effectiveness of a multi-level telehealth- based intervention to improve rural cancer care delivery
}

Tuya Pal ${ }^{1,2}$, Pamela C. Hull ${ }^{3,4}$, Tatsuki Koyama ${ }^{1,5}$, Phillip Lammers ${ }^{6}$, Denise Martinez ${ }^{7}$, Jacob McArthy ${ }^{7}$, Emma Schremp ${ }^{7}$, Ann Tezak², Anne Washburn', Jennifer G. Whisenant ${ }^{8}$ and Debra L. Friedman ${ }^{1,7^{*}}$

\begin{abstract}
Background: Despite lower cancer incidence rates, cancer mortality is higher among rural compared to urban dwellers. Patient, provider, and institutional level factors contribute to these disparities. The overarching objective of this study is to leverage the multidisciplinary, multispecialty oncology team from an academic cancer center in order to provide comprehensive cancer care at both the patient and provider levels in rural healthcare centers. Our specific aims are to: 1) evaluate the clinical effectiveness of a multi-level telehealth-based intervention consisting of provider access to molecular tumor board expertise along with patient access to a supportive care intervention to improve cancer care delivery; and 2) identify the facilitators and barriers to future larger scale dissemination and implementation of the multi-level intervention.
\end{abstract}

\footnotetext{
* Correspondence: Debra.l.friedman@vumc.org

${ }^{1}$ Vanderbilt-Ingram Cancer Center, 2220 Pierce Avenue, Nashville, TN 37232,

USA

${ }^{7}$ Division of Pediatric Hematology \& Oncology, Department of Pediatrics, Vanderbilt University Medical Center, 395 Preston Research Building, 2220 Pierce Avenue, Nashville, TN 37232, USA

Full list of author information is available at the end of the article
}

(c) The Author(s). 2021 Open Access This article is licensed under a Creative Commons Attribution 4.0 International License, which permits use, sharing, adaptation, distribution and reproduction in any medium or format, as long as you give appropriate credit to the original author(s) and the source, provide a link to the Creative Commons licence, and indicate if changes were made. The images or other third party material in this article are included in the article's Creative Commons licence, unless indicated otherwise in a credit line to the material. If material is not included in the article's Creative Commons licence and your intended use is not permitted by statutory regulation or exceeds the permitted use, you will need to obtain permission directly from the copyright holder. To view a copy of this licence, visit http://creativecommons.org/licenses/by/4.0/ The Creative Commons Public Domain Dedication waiver (http://creativecommons.org/publicdomain/zero/1.0/) applies to the data made available in this article, unless otherwise stated in a credit line to the data. 


\begin{abstract}
Methods: Coordinated by a National Cancer Institute-designated comprehensive cancer center, this study will include providers and patients across several clinics in two large healthcare systems serving rural communities. Using a telehealth-based molecular tumor board, sequencing results are reviewed, predictive and prognostic markers are discussed, and treatment plans are formulated between expert oncologists and rural providers. Simultaneously, the rural patients will be randomized to receive an evidence-based 6-week self-management supportive care program, Cancer Thriving and Surviving, versus an education attention control. Primary outcomes will be provider uptake of the molecular tumor board recommendation and patient treatment adherence. A mixed methods approach guided by the Consolidated Framework for Implementation Research that combines qualitative key informant interviews and quantitative surveys will be collected from both the patient and provider in order to identify facilitators and barriers to implementing the multi-level intervention.
\end{abstract}

Discussion: The proposed study will leverage information technology-enabled, team-based care delivery models in order to deliver comprehensive, coordinated, and high-quality cancer care to rural and/or underserved populations. Simultaneous attention to institutional, provider, and patient level barriers to quality care will afford the opportunity for us to broadly share oncology expertise and develop dissemination and implementation strategies that will enhance the cancer care delivered to patients residing within underserved rural communities.

Trial registration: Clinicaltrials.gov, NCT04758338. Registered 17 February 2021 - Retrospectively registered, http:// www.clinicaltrials.gov/

Keywords: Virtual molecular tumor board, Consolidated framework for implementation research (CFIR), Precision medicine

\section{Background}

Rationale

Several studies have documented elevated cancer incidence and/or mortality in rural compared to urban communities [1-7], particularly pronounced in certain regions of the United States (US), including the South [8]. These differences have broad population health implications as almost $20 \%$ of Americans live in rural areas $[8,9]$, but only $10 \%$ of physicians practice there [10]. Rural counties have some of the highest rates of poverty, where residents are faced with limited availability to cancer treatment and supportive care services, transportation barriers, and financial issues [11-15]. Similarly, challenges are faced by rural providers in delivering cancer care to their patients, with limited access to comprehensive care being the most important reason for outcome disparities [16]. Moreover, the growing divide in mortality between rural and urban dwellers $[1,5,17-$ 19] highlights the need to evaluate multi-level interventions directed at providers and their patients to improve outcomes.

Suggested strategies to enhance rural cancer care to alleviate issues associated with long travel distances comprise technology-based approaches to deliver remote care delivery, inclusive of education and supportive care [12]. Telehealth use in rural communities allows extension of care to wide geographic regions without patient or provider travel. An Institute of Medicine report noted that telehealth for rural hospitals drives volume and increases quality of care, while preserving low cost [20].
Telehealth has been successfully used for cancer screening, treatment, and supportive care [21-26], and been expanded even further especially in the post COVID-19 era [27-31].

Provision of optimal cancer care delivery also requires multispecialty and multidisciplinary input. Tumor boards contribute to such input and provide evidenceand consensus-based data to optimize cancer treatment and can be accessed virtually with interactive participation from large geographical regions [32-34]. With the advent of next generation sequencing (NGS), the use of tumor boards has expanded to meet new challenges faced for physicians and patients, with respect to interpretation of results and translation to clinical interventions. To meet this need, we and others have developed successful telehealth-based molecular tumor boards, which enable community oncologists to present cases in real time to an academic cancer center [35-37]. This is particularly salient in rural communities, where there are fewer oncologists and, subsequently, are faced with the challenge of being well versed in the rapidlychanging molecular architecture of multiple tumor types. Additionally, late stage disease at initial diagnosis may be more common in rural patients [4] where molecular tumor diagnostics are more likely to direct targeted treatments. Therefore, telehealth-based molecular tumor boards offer a mechanism to disseminate evidence-based information from a National Cancer Institute (NCI)-comprehensive cancer center to its rural catchment area. 


\section{Supportive care self-management interventions}

Self-management support is the systematic provision of education and supportive care to increase the patients' skills and confidence in managing their health problems and is an integral component of the Chronic Care Model [38-42]. Self-management interventions for cancer have been developed with face-to-face, online and telehealth models to minimize treatment-related symptoms and distress, improve treatment adherence and psychosocial wellbeing, and promote survival [39, 43-48]. The Chronic Disease Self-Management Program (CDSMP) is an evidence-based self-management intervention with demonstrated efficacy across numerous chronic health conditions with dissemination across the US, inclusive of rural communities, and to 25 countries [40, 49-53]. The CDSMP adaptation for cancer patients, Cancer Thriving and Surviving (CTS), has demonstrated efficacy in improving patient-provider communication, energy, and sleep, and reducing depression and stress-related problems $[48,54]$. Yet access to such programs is limited in rural communities with wide geographic areas. Therefore, evaluation of the effectiveness of the evidencebased CTS intervention delivered through telehealth among rural patients is needed given its potential to improve patient outcomes.

\section{Objectives and aims}

The goal of this project is to assess improvement in delivery of quality cancer care using a multi-level telehealth technology intervention tested at both the provider level and the patient level in the rural catchment area of Vanderbilt-Ingram Cancer Center (VICC), an NCIdesignated Comprehensive Cancer Center (Fig. 1). To achieve this goal, this study has two specific aims:

\section{Aim 1}

Evaluate the clinical effectiveness of a multi-level telehealth-based intervention for rural hospitals

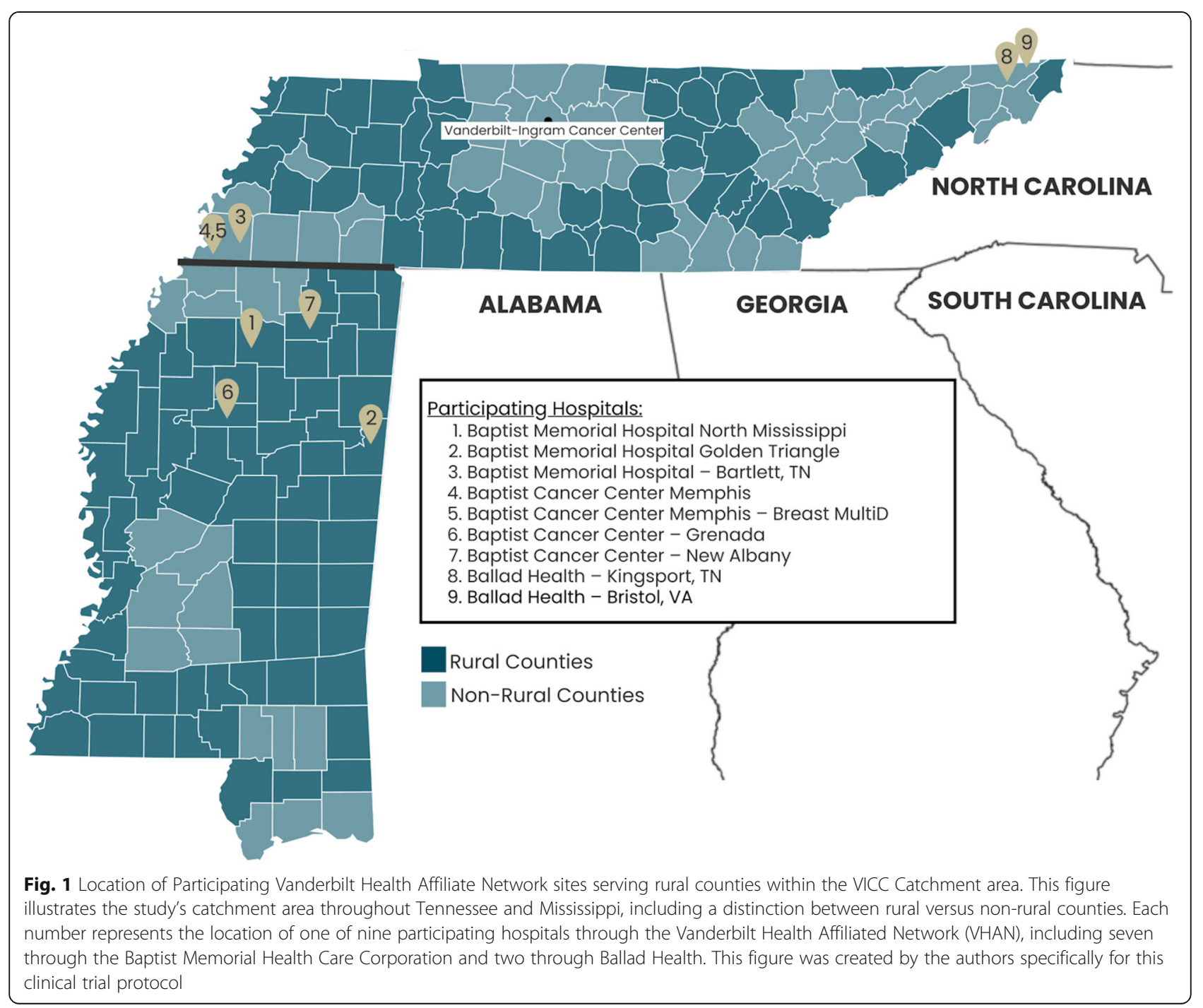


consisting of provider access to tumor board expertise that incorporates disease, patient, and molecular tumor characteristics, together with patient access to a supportive care intervention to improve cancer care delivery.

\section{Aim 2}

Identify the facilitators and barriers to future larger scale dissemination and implementation of the multi-level intervention, designed to enhance the quality of rural cancer care delivery.

\section{Conceptual framework for implementation}

In order to identify potential barriers and facilitators that may influence implementation and future dissemination and to understand "what 'works where and why' across multiple contexts" during and after implementation [55, 56], an implementation framework is helpful. The Consolidated Framework for Implementation Research (CFIR), a meta-theoretical framework that delineates a taxonomy of concepts to examine the process of implementation [55], was chosen for the current study as outlined in Fig. 2. The CFIR Outer Setting domain includes factors outside of the implementing organizations such as: patient needs and resources, the degree to which the hospitals are networked with external organizations (cosmopolitanism), peer competition with other hospitals, and external policies and incentives, such as evidence-based expert practice guidelines and criteria for treatment and reimbursement. The Inner Setting domain reflects characteristics of the organizations implementing the intervention (VICC and rural hospitals): structural characteristics (organization size, age, maturity), the nature and quality of organization's internal communications, general organizational culture, implementation climate (intention for change, compatibility, relative priority, organizational incentives, goals/ feedback, learning climate), and the organization's interventional readiness (leadership engagement, available resources for sustainability, access to information).

\section{Methods/design \\ Overall study design}

This study will utilize information technology (IT)-enabled, team-based care delivery models to provide comprehensive, coordinated, high-quality cancer-related care focused on rural populations. The study schema is presented in Fig. 3. We will evaluate the clinical effectiveness of a multi-level telehealth-based intervention in hospitals that see large volumes of rural patients. The intervention consists of provider access to tumor board expertise that incorporates disease, patient, and molecular tumor characteristics along with patient access to a supportive care intervention to improve cancer care delivery (Aim 1), and identification of facilitators and barriers to enable future larger scale dissemination and implementation of the multi-level intervention that is designed to enhance the quality of rural cancer care delivery (Aim 2). Simultaneous attention to institutional, provider, and patient level barriers to quality care will provide the opportunity for VICC, located in a region of

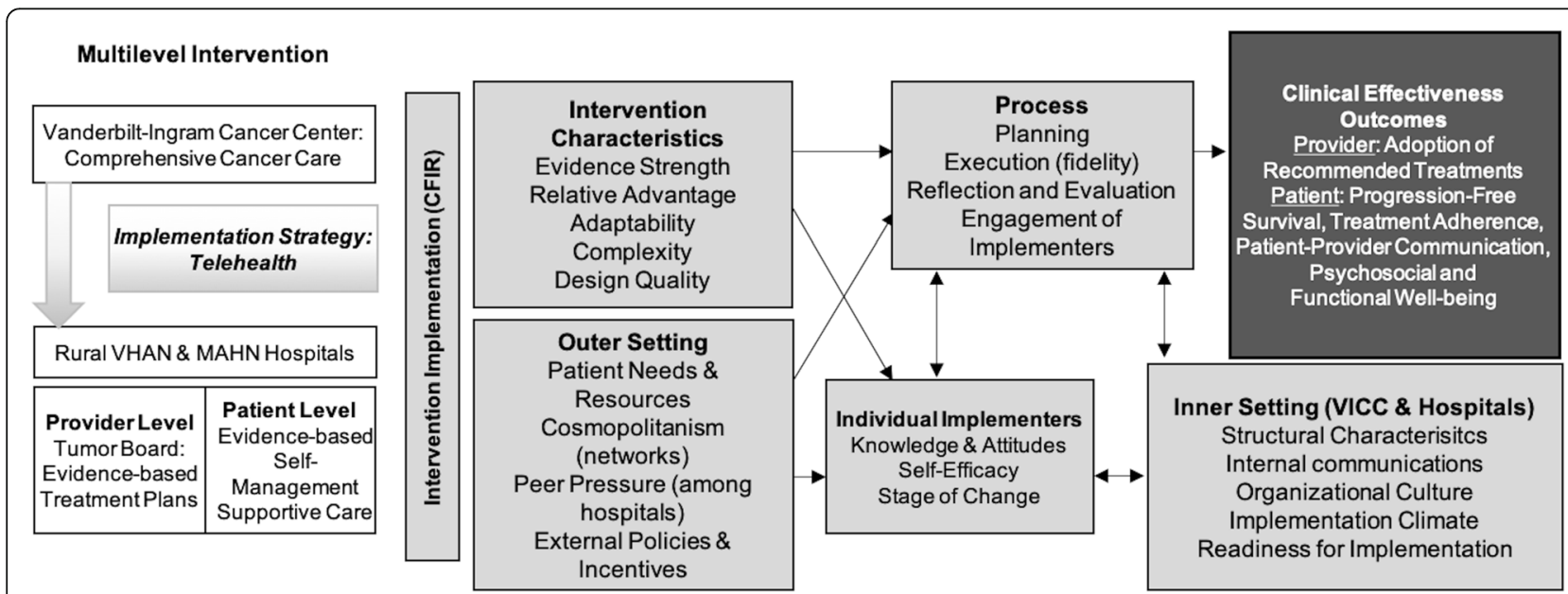

Fig. 2 Conceptual Framework: Implementation of Evidence-Based Cancer Care Delivery to Rural Populations via Telehealth. This figure illustrates the conceptual framework for implementation of the multi-level telehealth intervention to bring evidence-based comprehensive cancer care to patients in rural counties in Tennessee. The white blocks on the left indicate that we will evaluate the clinical effectiveness of delivering a multilevel telehealth intervention to rural hospitals to improve cancer care delivery, consisting of 1) provider-level access to tumor board expertise that incorporates disease, patient, and molecular tumor characteristics, and 2) patient-level access to a supportive care intervention (Aim 1). The dark gray block on the top right outlines the intervention outcomes. The gray blocks in the middle illustrate domains and subdomains of the CFIR that we will examine during intervention delivery to identify barriers and facilitators to future larger scale dissemination and implementation of the intervention (Aim 2) 


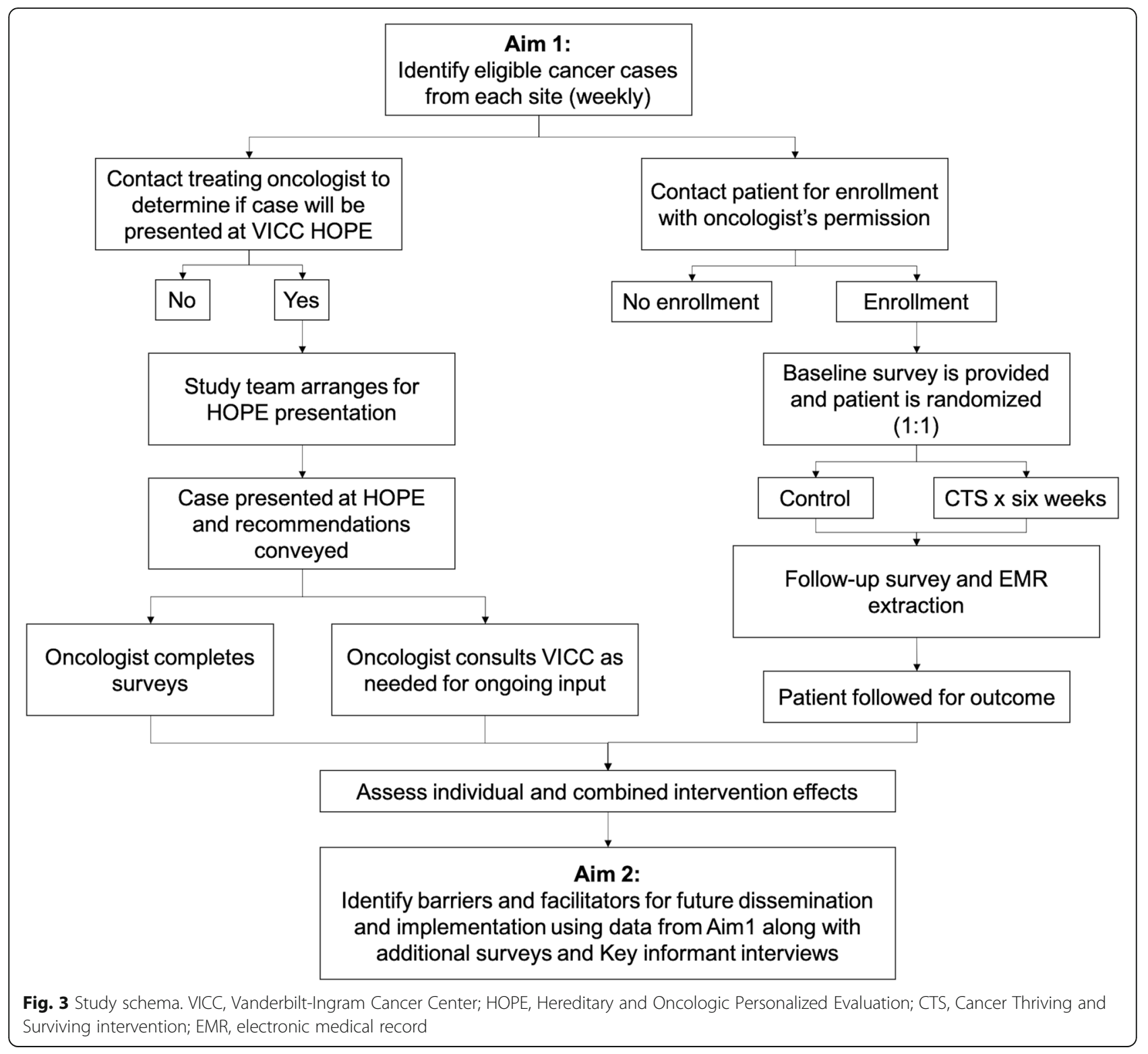

the country with some of the highest cancer mortality rates [57], to broadly share oncology expertise, as well as develop dissemination and implementation strategies to remotely enhance patient care to underserved rural communities.

\section{Study setting}

VICC is the sole NCI-designated Comprehensive Cancer Center in Tennessee serving adult as well as pediatric cancer patients. The geographic placement of VICC, as well as the regionally-renowned expertise in cancer care, presents a tremendous opportunity to develop strategies to address regional disparities in rural cancer care, including remote access to oncology expertise and supportive care.
Participating healthcare sites will include multiple oncology practices (i.e., cancer clinics) within the Vanderbilt Health Affiliated Network (VHAN), including the Baptist Memorial Health Care Corporation and Ballad Health. Participants will include oncology providers and patients at the aforementioned participating healthcare sites. The eligibility criteria are: 1) At least 21 years of age or older and English speaking with the ability to provide informed consent; 2) Oncology providers must treat patients within the designated VHAN oncology practices; 3) Patients with newly diagnosed or relapsed disease that are patients of the aforementioned oncology providers; and 4) Access to a reliable, video-capable device with internet access. 


\section{Data collection}

This study will implement provider-level and patientlevel interventions using a mixed-methods approach. The CFIR will be used to examine intervention delivery to identify barriers and facilitators to future dissemination and implementation of the intervention $[55,56]$. Both quantitative and qualitative data collection measures will be used, including baseline surveys before intervention implementation surveys, qualitative interviews, and follow-up surveys after intervention. Provider and patient recruitment along with the various surveys that will be conducted per study phase (i.e., Enrollment Phase, Tumor Board Phase, and Post-Intervention Phase) are presented in Fig. 4.

\section{Provider-level intervention and data collection}

The provider will be asked to complete a baseline survey to collect demographic information, including gender, age, race, ethnicity, and number of years post fellowship training. In addition to demographics, this survey will also assess the financial, emotional, and educational needs of rural cancer patients, and interest in expansion of telehealth services. To measure relative advantage (CFIR intervention characteristic), providers will be asked to rate on a scale of 1-10 the perceived need for remote access to the molecular tumor board, perceived importance of educational and selfmanagement interventions for their patients, and interest in participating in future research. An open-ended qualitative item will ask for suggestions of needed support for the intervention.
At the tumor board, genomic, histologic, and clinical data will be presented for further discussion and recommendations. The oncologist, with their patient, will decide if they will proceed with the recommendations, or alternatively, start another treatment. Recommendations and treatment changes will be collected.

Key informant interviews will be conducted with up to 10 participating oncologists at two points in time: 1) early implementation phase (six months after intervention initiation); and 2) maintenance phase (two years after initiation). The interview questions are adapted from the existing CFIR Interview Guide [58], covering the selected constructs under each of the five CFIR major domain. Interviews will be conducted by telephone using a semi-structured interview guide and will last about $20 \mathrm{~min}$; all interviews will be audio recorded.

\section{Patient-level intervention and data collection}

If the patient expresses interest in the study, the provider will confirm eligibility then prompt them to complete the informed consent. If reliable access to a device with video and internet access is not available, a device will be mailed to patient's home after they enroll and a data plan will be provided. These two resources will come at no cost to the patient, and the device will be returned at the conclusion of the study. Reasons for lack of participation will be tracked as a potential barrier to future dissemination.

Consented participants will be asked to complete a baseline survey to collect demographic information,

\begin{tabular}{|c|c|c|c|c|c|c|c|}
\hline \multicolumn{8}{|c|}{ PROVIDER LEVEL } \\
\hline \multirow[b]{2}{*}{$\frac{0}{\circ}$} & \multicolumn{2}{|c|}{ Enrollment Phase } & \multicolumn{2}{|c|}{ Tumor Board Phase } & \multicolumn{3}{|c|}{ Post-Intervention } \\
\hline & \multicolumn{2}{|c|}{$\begin{array}{l}\text { 1. Screen patients for eligibility } \\
\text { 2. Inform patient of the study: Tumor Board } \\
\text { presentation and intervention arms } \\
\text { a. Cancer Thrive \& Survive program } \\
\text { b. Self-navigated online program } \\
\text { 3. Research staff will input patient information } \\
\text { through REDCap database }\end{array}$} & $\begin{array}{c}\text { Contact study liaison to } \\
\text { arrange MTB } \\
\text { presentation }\end{array}$ & $\begin{array}{l}\text { PresentMTB } \\
\text { recommendations } \\
\text { to patient }\end{array}$ & $\begin{array}{l}\text { Monitor patient and } \\
\text { communicate w/MTB as } \\
\text { needed }\end{array}$ & $\begin{array}{l}\text { Follow patient throughout } \\
\text { treatment }\end{array}$ & $\begin{array}{l}\text { [If selected] } \\
\text { Participate in interview } 6 \\
\text { months post-intervention }\end{array}$ \\
\hline 空 & \multicolumn{2}{|c|}{$\begin{array}{l}\text { To be completed once: } \\
\text { 1. Provider Waiver of Consent } \\
\text { 2. Provider Baseline Needs Assessment } \\
\text { 3. Provider Demographic Questionnaire }\end{array}$} & \multicolumn{2}{|c|}{$\begin{array}{l}\text { To be completed once: } \\
\text { 1. MTB Questionnaire }\end{array}$} & & & $\begin{array}{l}\text { Qualitative Interviews via } \\
\text { phone }\end{array}$ \\
\hline \multicolumn{8}{|c|}{ PATIENT LEVEL } \\
\hline & Recruitment & Enrollment Phase & \multicolumn{2}{|c|}{ Tumor Board Phase } & \multicolumn{3}{|c|}{ Post-intervention } \\
\hline$\stackrel{5}{\frac{0}{0}}$ & $\begin{array}{l}\text { Receive } \\
\text { information about } \\
\text { study }\end{array}$ & Patient enrolls in study & $\begin{array}{l}\text { A. Participant is randon } \\
\text { following interv } \\
\text { - Cancer Thrive \& } S \\
\text { - Self-navigated onlin } \\
\text { B. Patient begins } 6 \text {. }\end{array}$ & $\begin{array}{l}\text { nized into one of the } \\
\text { ention arms } \\
\text { Survive program } \\
\text { e control program } \\
\text {-week program }\end{array}$ & \multicolumn{2}{|c|}{$\begin{array}{l}\text { Participant completes } 6 \text { outcome surveys } \\
\text { ( } \$ 25 \text { gift card incentive) }\end{array}$} & $\begin{array}{c}\text { [If selected] } \\
\text { Participant completes an } \\
\text { interview } 6 \text { months post- } \\
\text { intervention } \\
\text { (\$25 gift card incentive) }\end{array}$ \\
\hline 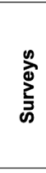 & & $\begin{array}{l}\text { Consent Form \& Initial Surveys: } \\
\text { 1. Baseline Needs Assessment } \\
\text { 2. Demographic Questionnaire } \\
\text { 3. Tumor Board Survey }\end{array}$ & $\begin{array}{l}\text { 1. Participation Lo } \\
\text { 2. Visual Analogue }\end{array}$ & $\begin{array}{l}\text { gs (CTS arm only) } \\
\text { Scale } 1 \& 2\end{array}$ & $\begin{array}{l}\text { 1. Post Needs Assess } \\
\text { 2. Distress Thermome } \\
\text { 3. Medical Adherence } \\
\text { 4. Functional Assessm } \\
\text { 5. MD Anderson Symp } \\
\text { Tool } \\
\text { 6. Communication Ass }\end{array}$ & $\begin{array}{l}\text { ment } \\
\text { ter } \\
\text { Visual Analogue Scale } 3 \\
\text { lent of Cancer Therapy- G } \\
\text { tom Inventory Assessment } \\
\text { essment tool }\end{array}$ & $\begin{array}{l}\text { Qualitative Interview via } \\
\text { phone }\end{array}$ \\
\hline
\end{tabular}

Fig. 4 Recruitment and surveys conducted at the provider level and patient level per study phase. The action and particular survey that will be completed by both the provider and patient for the Enrollment Phase, Tumor Board Phase, and Post-Intervention Phase is illustrated. MTB, molecular tumor board; CTS, Cancer Thriving and Surviving 
including race, ethnicity, highest level of education, annual household income, and zip code; age and gender will be extracted from the medical record. Participants will then be randomized (1:1) into the CTS Program Arm or Education Attention Control Arm (Fig. 3). Participants randomized to CTS will have a 6-week intervention delivered via telehealth using the VUMC telehealth services (Table 1).

Key informant interviews will be conducted with up to 25-30 patient participants in the CTS arm of the study approximately 6 months after the last session of the intervention. An index combining all of the patient-level outcome variables at pre-intervention and post-intervention will be created to calculate the pre-post difference with positive values indicating an improvement and negative values indicating a decrease. The interview questions are adapted from the existing CFIR Interview Guide [58], covering the selected constructs under each of the five CFIR major domain. Interviews will be conducted by telephone using a semi-structured interview guide and lasting about 20 min; all interviews will be audio recorded.

Participants in the Education Attention Control Arm will receive publicly available online educational materials compiled in a password protected website that broadly covers the same topics as the CTS syllabus and enables the study team to track how the participant navigates through these educational materials. All materials are drawn from preexisting public domains such as the National Institutes of Health, NCI, and the American Society of Clinical Oncology.

\section{Data analysis}

Data will be analyzed sequentially in three phases: quantitative-qualitative-quantitative (i.e., baseline survey, interviews, and follow-up surveys). We will use connecting processes to combine both types of data, thus allowing one dataset to build upon another dataset in each sequential phase.

\section{Process evaluation data}

Implementation penetration will be assessed as a ratio of number of patients who participate in each group divided by total number of potential participants at each recruitment site. The recruitment rate will be calculated as the number of weeks required to recruit at least eight participants in each arm of the patient-level component. To address execution, three dimensions of intervention fidelity for the CTS program will be measured. Adherence of the group facilitators to the CTS protocol will be measured using an adapted Fidelity Checklist [59] completed by the facilitators to document completion of required activities. Exposure of patients to the intervention will be measured using participation/attendance logs and website analytics on usage of the online information. Participant responsiveness will be measured as satisfaction with the intervention from the post surveys. These measures will be combined into a fidelity score. Other data collected will include patient cancer type and stage, institution size, practice size, and number of rural counties with persistent poverty served and deprivation index, as indicators of structural characteristics.

\section{Qualitative data}

Audio recordings will be transcribed with no identifiers. Qualitative software (e.g., ATLAS.ti or RQDA) will be used to code the transcripts using the CFIR Codebook Template [58]. A thematic analysis method to identify and analyze commonly recurring themes will be used

Table 1 Cancer Surviving and Thriving Syllabus

Week 1:
- Introduction to the Workshop
- Group Introductions
- The Mind/Body Connection/Distraction
- Fatigue Management and Getting Help
- Introduction to Action Plans
Week 2:
- Feedback/Problem Solving
- Dealing with Difficult Emotions
- Getting a Good Night's Sleep
- Regaining Fitness During and after Cancer Treatment
- Making an Action Plan

Week 3:

- Feedback

- Managing Plan

- Living with Uncertainty

- Making Decisions

- Future Plans for Healthcare

- Making an Action Plan

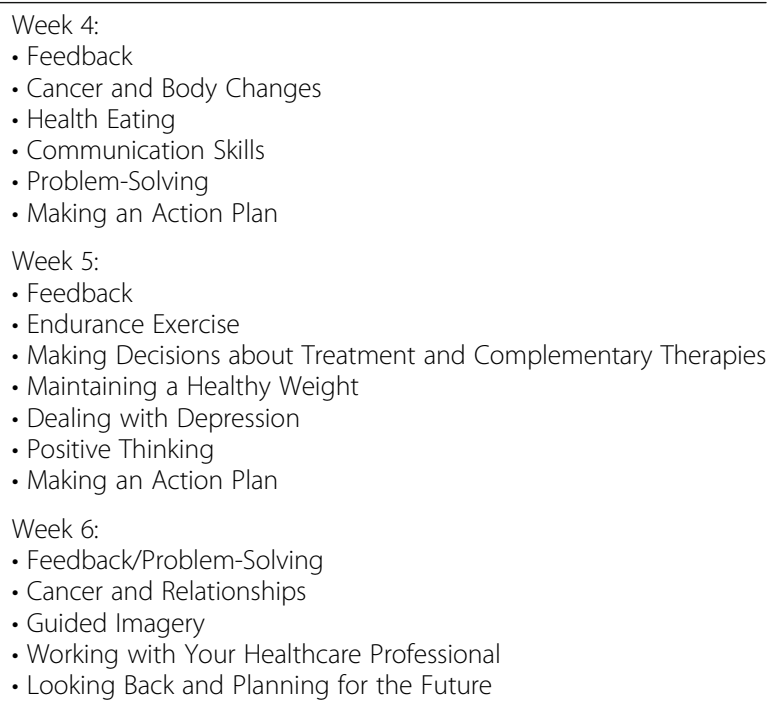


[60], then themes will be summarized for each group. Open-ended qualitative responses from surveys will be coded into categories based on emergent themes, then merged with the quantitative data sets as categorical variables.

\section{Quantitative data and intervention outcomes}

Survey data will primarily be summarized with descriptive statistics (i.e., frequencies/percentages for categorical variables and means/standard deviations for continuous variables) along with bivariate comparisons across sites and between provider and patient data, where appropriate using chi-squared tests, t-tests, and analysis of variance.

The primary outcomes will be provider uptake of the VICC HOPE molecular tumor board treatment recommendation and patient treatment adherence. Secondary outcomes include progression-free survival (PFS), patient functional and psychosocial well-being, and patientprovider communication. Outcomes will be compared between the CTS and attention control groups. Table 2 provides a list of the tools that will be utilized to measure these outcomes.

For the provider primary outcome, a logistic regression model will be fit with the following patient-level, provider-level, and institution-level variables as potential effect modifiers. Patient-level includes: cancer type, race, ethnicity, age and gender; provider-level includes: age, years since completion of fellowship training, race, ethnicity, gender; and institution-level includes: institution size (number of inpatient beds and outpatient infusion chairs), practice size (oncologists, nurses, advanced practice providers) and number of rural counties with persistent poverty served. Note that the outcome will most likely be correlated within the same provider, and to account for this correlation, we will use generalized estimating equations (GEE) with an independent weight matrix. Because the CTS Program Arm will be delivered to a group of 8 to 10 patients at a time, we will consider this as a crossed random effect. The Education Attention Control Arm will not have groups, and we will treat each individual as their own group to fit the model. Institution-level data will be used as fixed effects.

The secondary endpoints will be analyzed similarly using the regression approach taking into account the potential clustering effect of the treatment delivery group and practice. For a continuous outcome, mixedeffects model will be used; for PFS, we will use mixed effects Cox regression model to account for the intervention group clusters.

\section{Sample size and power analysis}

We expect to present 450 cases to the molecular tumor board, and we expect 300 patients to be randomized at 1 to 1 to the two treatment groups. For the patient-level intervention, we can detect treatment effect (difference in binary outcome) if the true successful (adherence) proportions are $75 \%$ (telehealth) and $60 \%$ (control) with $80 \%$ power while controlling type I error rate at $5 \%$.

\section{Discussion}

Participation in this study will directly test the clinical effectiveness of a telehealth implementation strategy for disseminating genomic cancer information for optimal patient care across diverse communities within and beyond the catchment area of VICC. This will allow iterative development of best practices for cancer care delivery to rural communities. This study is testing a novel multi-level intervention with simultaneous evaluation of provider and patient components to improve cancer care among underserved individuals in rural communities. A multi-level intervention to assess improvement in delivery of quality cancer care will be tested: 1) at the provider level through access to an existing telehealth-based molecular tumor board and availability to disease-specific expertise at VICC; and 2) the patient level through a telehealth-based supportive care intervention.

Using the CFIR model, we chose a multi-level intervention that includes both provider and patient level components. However, as such, it may be difficult to determine the relative contribution of each of the

Table 2 Assessment surveys that will be used to evaluate outcomes from the provider and patient

\begin{tabular}{|c|c|}
\hline Name of Tool & Measurement \\
\hline The Visual Analogue Scale [61] & $\begin{array}{l}\text { Patients mark a line at the point along a continuum showing how much of each drug they have taken in the } \\
\text { past month }\end{array}$ \\
\hline The Distress Thermometer [62] & Level of patient distress (0-10 scale) and problems contributing to it \\
\hline $\begin{array}{l}\text { The Functional Assessment of Cancer } \\
\text { Therapy [63] }\end{array}$ & $\begin{array}{l}\text { Health related quality of life in four primary domains: physical well-being, social/family well-being, emotional } \\
\text { well-being, and functional well-being }\end{array}$ \\
\hline $\begin{array}{l}\text { The MD Anderson Symptom } \\
\text { Inventory [64] }\end{array}$ & $\begin{array}{l}\text { Thirteen common symptoms faced by cancer patients for severity and interference with aspects of daily life } \\
\text { on a 10-point numeric rating scale }\end{array}$ \\
\hline $\begin{array}{l}\text { The Communication Assessment Tool } \\
\text { [65] }\end{array}$ & $\begin{array}{l}\text { Patients rate communication with the physician on a 15-item instrument that employs a five-point response } \\
\text { scale }\end{array}$ \\
\hline
\end{tabular}


components. To overcome this limitation, we have developed some analyses of each component for Aim 1 and will look across institutional, provider, and patient levels for barriers and facilitators for future larger scale implementation in Aim 2. In addition, there may be cases with only an oncologist or patient participant. While we don't expect this to be a high number, discordant participation will reflect real world circumstances and inform future dissemination and implementation strategies.

As with all telehealth services, this study could be challenged by technical difficulties. However, VICC has successfully brought telehealth into rural counties with low broadband connectivity. This includes combined use of computers, tablets and smart phones for the participants. To date, we have had no issues with VICC telehealth across a number of service lines and research projects. Additionally, through the Vanderbilt University Medical Center (VUMC), an institutional infrastructure exists for healthcare providers to deliver telehealth-based services. This existing VUMC telehealth infrastructure and software is available for use in the proposed study and access to broadband and devices will be provided to participants if needed. This will inform future scaling of this intervention.

\section{Summary and impact}

With the proposed multi-level remote intervention, we will 1) improve comprehensive cancer care delivery to patients residing in rural communities with persistent poverty; 2) use telehealth to broaden the reach of our NCI-designated comprehensive cancer center in these communities; 3) disseminate evidence-based information to rural oncology providers using a tumor board to share expertise in molecular tumor analysis and interpretation; 4) provide guidance on cutting-edge therapies based on patient, disease, and tumor characteristics; and 5) offer an evidence-based self-management intervention to rural patients. Furthermore, we will collect data for future dissemination and implementation of this intervention in order to decrease disparities in rural cancer patients with limited access to comprehensive care.

\section{Abbreviations}

CDSMP: Chronic Disease Self-Management Program; CFIR: Consolidated Framework for Implementation Research; CTS: Cancer Thriving and Surviving: GEE: Generalized estimating eqs.; IT: Information technology; NCl: National Cancer Institute; NGS: Next generation sequencing; PFS: Progression-free survival; US: United States; VHAN: Vanderbilt Health Affiliated Network; VICC: Vanderbilt-Ingram Cancer Center; VUMC: Vanderbilt University Medical Center

\section{Supplementary Information}

The online version contains supplementary material available at https://doi. org/10.1186/s12885-021-08949-4.

Additional file 1.

\section{Acknowledgements}

Not applicable.

\section{Authors' contributions}

TP and DLF are project Co-PIs and lead the research team. TP, DLF, PCH, and $\mathrm{PL}$ collaborated to develop the study design and objectives. TK designed the statistical analysis plan. ES, AT, DM, JM, and AW are key members of the research team that will manage the study. TP, DLF, and JGW prepared the manuscript for publication. All authors read and approved the final manuscript.

\section{Funding}

This study is supported by the National Institutes of Health through funding from the National Cancer Institute (R01CA240093). This funding source is solely providing funding for the study; they are not participating in the research study. This study was also supported by CTSA award from the National Center for Advancing Translational Sciences (UL 1TR000445). Its contents are solely the responsibility of the authors and do not necessarily represent official views of the National Center for Advancing Translational Sciences or the National Institutes of Health. This funding source provided the funding necessary to develop and maintain the REDCap ${ }^{\circledR}$ online software, which is a tool this study is using to collect informed consent and survey responses from participants. This funding source is not paying for the study proposed in this manuscript and is not participating in the research.

\section{Availability of data and materials}

Not applicable. Sharing of data generated from this study will adhere to the National Institutes of Health guidelines regarding sharing of data collected using federal funds.

\section{Declarations}

\section{Ethics approval and consent to participate}

The Institutional Review Board at Vanderbilt University (IRB \#200101) will serve as the single IRB coordinating center for all participating oncology clinics. All participating clinics will submit IRB approval and supporting documentation prior to consenting and enrolling a participant. All participants will provide written informed consent to participate.

Consent for publication

Not applicable.

\section{Competing interests}

The authors declare that they have no competing interests.

\section{Author details}

${ }^{1}$ Vanderbilt-Ingram Cancer Center, 2220 Pierce Avenue, Nashville, TN 37232, USA. ${ }^{2}$ Division of Genetic Medicine, Department of Medicine, Vanderbilt University Medical Center, 2220 Pierce Avenue, 536 Robinson Research Building, Nashville, TN 37232, USA. ${ }^{3}$ University of Kentucky Markey Cancer Center, 800 Rose Street, Lexington, KY 40536, USA. ${ }^{4}$ Department of Behavioral Science, University of Kentucky College of Medicine, Rural and Underserved Health Research Center, Healthy Kentucky Research Building, 760 Press Avenue, Lexington, KY 40536, USA. 5Department of Biostatistics, Vanderbilt University Medical Center, 2525 West End, Suite 1100, Nashville, TN 37203, USA. ${ }^{6}$ Baptist Cancer Center, 80 Humphreys Center Suite 330, Memphis, TN 38120, USA. ${ }^{7}$ Division of Pediatric Hematology \& Oncology, Department of Pediatrics, Vanderbilt University Medical Center, 395 Preston Research Building, 2220 Pierce Avenue, Nashville, TN 37232, USA. ${ }^{8}$ Division of Hematology \& Oncology, Department of Medicine, Vanderbilt University Medical Center, 1161 21st Avenue South, Nashville, TN 37232, USA.

Received: 5 August 2021 Accepted: 1 November 2021

Published online: 23 November 2021

\section{References}

1. Henley SJ, Anderson RN, Thomas CC, Massetti GM, Peaker B, Richardson LC. Invasive Cancer incidence, 2004-2013, and deaths, 2006-2015, in nonmetropolitan and metropolitan counties - United States. MMWR Surveill Summ. 2017;66(14):1-13. https://doi.org/10.15585/mmwr.ss6614a1. 
2. Blake KD, Moss JL, Gaysynsky A, Srinivasan S, Croyle RT. Making the Case for Investment in Rural Cancer Control: an analysis of rural Cancer incidence, mortality, and funding trends. Cancer Epidemiol Biomark Prev. 2017;26(7): 992-7. https://doi.org/10.1158/1055-9965.EPI-17-0092.

3. Chow CJ, Al-Refaie WB, Abraham A, Markin A, Zhong W, Rothenberger DA, et al. Does patient rurality predict quality colon cancer care?: a populationbased study. Dis Colon Rectum. 2015;58(4):415-22. https://doi.org/10.1097/ DCR.0000000000000173.

4. Meilleur A, Subramanian SV, Plascak JJ, Fisher JL, Paskett ED, Lamont EB. Rural residence and cancer outcomes in the United States: issues and challenges. Cancer Epidemiol Biomark Prev. 2013;22(10):1657-67. https://doi. org/10.1158/1055-9965.EPI-13-0404.

5. Singh GK, Williams SD, Siahpush M, Mulhollen A. Socioeconomic, ruralurban, and racial inequalities in US Cancer mortality: part l-all cancers and lung Cancer and part II-colorectal, prostate, breast, and cervical cancers. J Cancer Epidemiol. 2011;2011:107497-27. https://doi.org/10.1155/2011/1074 97.

6. Kinney AY, Harrell J, Slattery M, Martin C, Sandler RS. Rural-urban differences in colon cancer risk in blacks and whites: the North Carolina Colon Cancer study. J Rural Health. 2006;22(2):124-30. https://doi.org/10.1111/j.1748-03 61.2006.00020.x.

7. Hashibe M, Kirchhoff AC, Kepka D, Kim J, Millar M, Sweeney C, et al. Disparities in cancer survival and incidence by metropolitan versus rural residence in Utah. Cancer Med. 2018;7(4):1490-7. https://doi.org/10.1002/ca m4.1382.

8. Zahnd WE, James AS, Jenkins WD, Izadi SR, Fogleman AJ, Steward DE, et al. Rural-urban differences in Cancer incidence and trends in the United States. Cancer Epidemiol Biomark Prev. 2018;27(11):1265-74. https://doi.org/10.11 58/1055-9965.EPI-17-0430.

9. United States Census Bureau American Community Survey, 2011-2015. New Census Data Show Differences Between Urban and Rural Populations. [https:/www.census.gov/newsroom/press-releases/2016/cb16-210.html].

10. National Rural Health Information. About Rural Health Care [https://www. ruralhealthweb.org/about-nrha/about-rural-health-care]

11. Weaver KE, Geiger AM, Lu L, Case LD. Rural-urban disparities in health status among US cancer survivors. Cancer. 2013;119(5):1050-7. https://doi.org/10.1 002/cncr.27840

12. Charlton M, Schlichting J, Chioreso C, Ward M, Vikas P. Challenges of rural Cancer Care in the United States. Oncology (Williston Park). 2015;29(9):63340.

13. McDougall JA, Banegas MP, Wiggins CL, Chiu VK, Rajput A, Kinney AY. Rural disparities in treatment-related financial hardship and adherence to surveillance colonoscopy in diverse colorectal Cancer survivors. Cancer Epidemiol Biomark Prev. 2018;27(11):1275-82. https://doi.org/10.1158/10559965.EPI-17-1083.

14. Andrykowski MA, Steffens RF, Bush HM, Tucker TC. Disparities in mental health outcomes among lung cancer survivors associated with ruralness of residence. Psycho-oncology. 2014;23(4):428-36. https://doi.org/10.1002/ pon.3440.

15. Reid-Arndt SA, Cox CR. Does rurality affect quality of life following treatment for breast cancer? J Rural Health. 2010;26(4):402-5. https://doi. org/10.1111/j.1748-0361.2010.00295.x.

16. Unger JM, Moseley A, Symington B, Chavez-MacGregor M, Ramsey SD, Hershman DL. Geographic distribution and survival outcomes for rural patients with Cancer treated in clinical trials. JAMA Netw Open. 2018;1(4): e181235. https://doi.org/10.1001/jamanetworkopen.2018.1235.

17. Spencer JC, Wheeler SB, Rotter JS, Holmes GM. Decomposing mortality disparities in urban and rural U.S. counties. Health Serv Res. 2018;53(6):431031. https://doi.org/10.1111/1475-6773.12982

18. Singh GK, Jemal A. Socioeconomic and racial/ethnic disparities in Cancer mortality, incidence, and survival in the United States, 1950-2014: over six decades of changing patterns and widening inequalities. J Environ Public Health. 2017;2017:2819372-19. https://doi.org/10.1155/2017/2819372.

19. Singh GK, Miller BA, Hankey BF. Changing area socioeconomic patterns in U. S. cancer mortality, 1950-1998: Part II-lung and colorectal cancers. J Natl Cancer Inst. 2002;94(12):916-25. https://doi.org/10.1093/jnci/94.12.916.

20. Institute of Medicine. The Role of Telehealth in an Evolving Health Care Environment. Washington, DC: The National Academies Press; 2012

21. Jue JS, Spector SA, Spector SA. Telemedicine broadening access to care for complex cases. J Surg Res. 2017;220:164-70. https://doi.org/10.1016/j.jss.201 7.06.085.
22. Larson $J$, Rosen $A B$, Wilson $F A$. The effect of telehealth interventions on quality of life of Cancer patients: a systematic review and Meta-analysis. Telemed J E Health. 2018;24(6):397-405. https://doi.org/10.1089/tmj.2017. 0112

23. Rocque GB, Halilova KI, Varley AL, Williams CP, Taylor RA, Masom DG, et al. Feasibility of a telehealth educational program on self-Management of Pain and Fatigue in adult Cancer patients. J Pain Symptom Manag. 2017;53(6): 1071-8. https://doi.org/10.1016/j.jpainsymman.2016.12.345.

24. Jaglal SB, Haroun VA, Salbach NM, Hawker G, Voth J, Lou W, et al. Increasing access to chronic disease self-management programs in rural and remote communities using telehealth. Telemed J E Health. 2013;19(6):467-73. https://doi.org/10.1089/tmj.2012.0197.

25. Cox A, Lucas G, Marcu A, Piano M, Grosvenor W, Mold F, et al. Cancer Survivors' experience with telehealth: a systematic review and thematic synthesis. J Med Internet Res. 2017;19(1):e11. https://doi.org/10.2196/jmir. 6575

26. Kinney AY, Boonyasiriwat W, Walters ST, Pappas LM, Stroup AM, Schwartz $M D$, et al. Telehealth personalized cancer risk communication to motivate colonoscopy in relatives of patients with colorectal cancer: the family CARE randomized controlled trial. J Clin Oncol. 2014;32(7):654-62. https://doi. org/10.1200/JCO.2013.51.6765.

27. Myers Virtue S, Howrey HL, Duffy NM, Wallace M. Shifting psychosocial oncology care to telepsychology during the COVID-19 pandemic. J Psychosoc Oncol. 2021;39(3):416-27. https://doi.org/10.1080/07347332.2 021.1894526.

28. Berlin A, Lovas M, Truong T, Melwani S, Liu J, Liu ZA, et al. Implementation and outcomes of virtual care across a tertiary Cancer center during COVID19. JAMA Oncol. 2021;7(4):597-602. https://doi.org/10.1001/jamaoncol.2020. 6982

29. Knoerl R, Phillips CS, Berfield J, Woods H, Acosta M, Tanasijevic A, et al. Lessons learned from the delivery of virtual integrative oncology interventions in clinical practice and research during the COVID-19 pandemic. Support Care Cancer. 2021;29(8):4191-4. https://doi.org/10.1007/ s00520-021-06174-0.

30. Royce TJ, Sanoff HK, Rewari A. Telemedicine for Cancer Care in the Time of COVID-19. JAMA Oncol. 2020;6(11):1698-9. https://doi.org/10.1001/jama oncol.2020.2684

31. Ben-Arye E, Paller CJ, Lopez AM, White S, Pendleton E, Kienle GS, et al. The Society for Integrative Oncology Practice Recommendations for online consultation and treatment during the COVID-19 pandemic. Support Care Cancer. 2021;29(10):6155-65. https://doi.org/10.1007/s00520-021-06205-w.

32. Stevenson MM, Irwin T, Lowry T, Ahmed MZ, Walden TL, Watson M, et al. Development of a virtual multidisciplinary lung cancer tumor board in a community setting. J Oncol Pract. 2013;9(3):e77-80. https://doi.org/10.1200/ JOP.2013.000882.

33. Louis JS, Bukowski A, Rodrigues AN, Moreno J, Ferreyra M, Lopes A, et al. Global Cancer Institute multidisciplinary tumor boards as a tool to improve patterns of clinical practice for breast and gynecologic cancer in resourcelimited settings. J Clin Oncol. 2017;35(15_suppl):6556.

34. El Saghir NS, Keating NL, Carlson RW, Khoury KE, Fallowfield L. Tumor boards: optimizing the structure and improving efficiency of multidisciplinary management of patients with cancer worldwide. Am Soc Clin Oncol Educ Book. 2014;(34):e461-6. https://doi.org/10.14694/EdBook_A M.2014.34.e461.

35. Dalton WB, Forde PM, Kang H, Connolly RM, Stearns V, Gocke CD, et al. Personalized Medicine in the Oncology Clinic: Implementation and Outcomes of the Johns Hopkins Molecular Tumor Board. JCO Precis Oncol. 2017;2017(1):1-19. https://doi.org/10.1200/PO.16.00046.

36. Rody A, Ettl J, Marme F, Prat A. Molecular Tumor Boards. Breast Care (Basel). 2018;13(2):141-3. https://doi.org/10.1159/000489138.

37. Schwaederle M, Parker BA, Schwab RB, Fanta PT, Boles SG, Daniels GA, et al. Molecular tumor board: the University of California-san Diego Moores Cancer Center experience. Oncologist. 2014;19(6):631-6. https://doi.org/10.1 634/theoncologist.2013-0405.

38. Barr VJ, Robinson S, Marin-Link B, Underhill L, Dotts A, Ravensdale D, et al. The expanded chronic care model: an integration of concepts and strategies from population health promotion and the chronic care model. Hosp Q. 2003;7(1):73-82. https://doi.org/10.12927/hcq.2003.16763.

39. Coffey L, Mooney O, Dunne S, Sharp L, Timmons A, Desmond D, et al. Cancer survivors' perspectives on adjustment-focused self-management 
interventions: a qualitative meta-synthesis. J Cancer Surviv. 2016;10(6):101234. https://doi.org/10.1007/s11764-016-0546-3.

40. Lorig KR, Holman H. Self-management education: history, definition, outcomes, and mechanisms. Ann Behav Med. 2003;26(1):1-7. https://doi. org/10.1207/S15324796ABM2601_01.

41. Wagner $\mathrm{EH}$. Chronic disease management: what will it take to improve care for chronic illness? Eff Clin Pract. 1998;1(1):2-4.

42. Wagner EH, Austin BT, Davis C, Hindmarsh M, Schaefer J, Bonomi A. Improving chronic illness care: translating evidence into action. Health affairs (Project Hope). 2001;20(6):64-78. https://doi.org/10.1377/hlthaff.20.6. 64.

43. Bantum EO, Albright CL, White KK, Berenberg JL, Layi G, Ritter PL, et al. Surviving and thriving with cancer using a web-based health behavior change intervention: randomized controlled trial. J Med Internet Res. 2014; 16(2):e54. https://doi.org/10.2196/jmir.3020.

44. Foster C, Grimmett C, May CM, Ewings S, Myall M, Hulme C, et al. A webbased intervention (RESTORE) to support self-management of cancer-related fatigue following primary cancer treatment: a multi-Centre proof of concept randomised controlled trial. Support Care Cancer. 2016;24(6):2445-53. https://doi.org/10.1007/s00520-015-3044-7.

45. Gao WJ, Yuan CR. Self-management programme for cancer patients: a literature review. Int Nurs Rev. 2011;58(3):288-95. https://doi.org/10.1111/j.14 66-7657.2011.00907.x.

46. Howell D, Harth T, Brown J, Bennett C, Boyko S. Self-management education interventions for patients with cancer: a systematic review. Support Care Cancer. 2017;25(4):1323-55. https://doi.org/10.1007/s00520-01 6-3500-z.

47. McCorkle R, Ercolano E, Lazenby M, Schulman-Green D, Schilling LS, Lorig K, et al. Self-management: enabling and empowering patients living with cancer as a chronic illness. CA Cancer J Clin. 2011;61(1):50-62. https://doi. org/10.3322/caac.20093.

48. Risendal BC, Dwyer A, Seidel RW, Lorig K, Coombs L, Ory MG. Meeting the challenge of cancer survivorship in public health: results from the evaluation of the chronic disease self-management program for cancer survivors. Front Public Health. 2014;2:214. https://doi.org/10.3389/fpubh.2 014.00214.

49. Erdem E, Korda H. Self-management program participation by older adults with diabetes: chronic disease self-management program and diabetes selfmanagement program. Fam Community Health. 2014;37(2):134-46. https:// doi.org/10.1097/FCH.0000000000000025.

50. Brady TJ, Murphy L, O'Colmain BJ, Beauchesne D, Daniels B, Greenberg M, et al. A meta-analysis of health status, health behaviors, and health care utilization outcomes of the chronic disease self-management program. Prev Chronic Dis. 2013;10:120112. https://doi.org/10.5888/pcd10.120112.

51. Kennedy A, Reeves D, Bower P, Lee V, Middleton E, Richardson G, et al. The effectiveness and cost effectiveness of a national lay-led self care support programme for patients with long-term conditions: a pragmatic randomised controlled trial. J Epidemiol Community Health. 2007;61(3):25461. https://doi.org/10.1136/jech.2006.053538.

52. Lorig KR, Ritter P, Stewart AL, Sobel DS, Brown BW Jr, Bandura A, et al. Chronic disease self-management program: 2-year health status and health care utilization outcomes. Med Care. 2001;39(11):1217-23. https://doi.org/1 0.1097/00005650-200111000-00008.

53. Smith ML, Towne SD, Herrera-Venson A, Cameron K, Kulinski KP, Lorig K, et al. Dissemination of Chronic Disease Self-Management Education (CDSM E) Programs in the United States: Intervention Delivery by Rurality. Int J Environ Res Public Health. 2017;14(6). https://doi.org/10.3390/ijerph1406063 8.

54. Risendal B, Dwyer A, Seidel R, Lorig K, Katzenmeyer C, Coombs L, et al. Adaptation of the chronic disease self-management program for cancer survivors: feasibility, acceptability, and lessons for implementation. J Cancer Educ. 2014;29(4):762-71. https://doi.org/10.1007/s13187-014-0652-8.

55. Damschroder LJ, Aron DC, Keith RE, Kirsh SR, Alexander JA, Lowery JC. Fostering implementation of health services research findings into practice: a consolidated framework for advancing implementation science. Implement Sci. 2009:4(1):50. https://doi.org/10.1186/1748-5908-4-50.

56. Nilsen P. Making sense of implementation theories, models and frameworks. Implement Sci. 2015;10(1):53. https://doi.org/10.1186/s13012-015-0242-0.

57. U.S. Cancer Statistics Working Group. U.S. Cancer Statistics Data Visualizations Tool, based on 2019 submission data (1999-2017): U.S Department of Health and Human Services, Centers for Disease Control and
Prevention and National Cancer Institute [https://gis.cdc.gov/Cancer/USCS/ DataViz.html].

58. Consolidated Framework for Implementation Research. Center for Clinical Management Research. [https://cfirguide.org].

59. Breitenstein SM, Fogg L, Garvey C, Hill C, Resnick B, Gross D. Measuring implementation fidelity in a community-based parenting intervention. Nurs Res. 2010;59(3):158-65. https://doi.org/10.1097/NNR.0b013e3181dbb2e2.

60. V. B, Clarke V. Using thematic analysis in psychology. Qual Res Psychol. 2006; 3(2):77-101. https://doi.org/10.1191/1478088706qp063oa.

61. Kalichman SC, Amaral CM, Swetzes C, Jones M, Macy R, Kalichman MO, et al A simple single-item rating scale to measure medication adherence: further evidence for convergent validity. J Int Assoc Physicians AIDS Care (Chic) 2009;8(6):367-74. https://doi.org/10.1177/1545109709352884.

62. National Comprehensive Cancer Network. Distress Thermometer Scale. [http://www.nccn.org/professionals/physician_gls/pdf/distress.pdf].

63. Cella DF, Tulsky DS, Gray G, Sarafian B, Linn E, Bonomi A, et al. The functional assessment of Cancer therapy scale: development and validation of the general measure. J Clin Oncol. 1993;11(3):570-9. https://doi.org/10.12 00/JCO.1993.11.3.570.

64. Cleeland CS, Mendoza TR, Wang XS, Chou C, Harle MT, Morrissey M, et al. Assessing symptom distress in cancer patients: the M.D. Anderson symptom inventory. Cancer. 2000;89(7):1634-46. https://doi.org/10.1002/1097-0142 (20001001)89:7<1634:..AID-CNCR29>3.0.CO;2-V.

65. Makoul G, Krupat E, Chang CH. Measuring patient views of physician communication skills: development and testing of the communication assessment tool. Patient Educ Couns. 2007;67(3):333-42. https://doi.org/10.1 016/j.pec.2007.05.005.

\section{Publisher's Note}

Springer Nature remains neutral with regard to jurisdictional claims in published maps and institutional affiliations.
Ready to submit your research? Choose BMC and benefit from:
- fast, convenient online submission
- thorough peer review by experienced researchers in your field
- rapid publication on acceptance
- support for research data, including large and complex data types
- gold Open Access which fosters wider collaboration and increased citations
- maximum visibility for your research: over $100 \mathrm{M}$ website views per year
At BMC, research is always in progress.
Learn more biomedcentral.com/submissions 